\title{
Creating a sense of place with a deliberately constrained virtual environment
}

\section{Phil Turner* and Susan Turner}

School of Computing, Edinburgh Napier University,

10 Colinton Road, Edinburgh, EH10 5DT, UK

E-mail: p.turner@napier.ac.uk E-mail: s.turner@napier.ac.uk

${ }^{*}$ Corresponding author

\section{Luke Burrows}

User Vision Edinburgh, 55 North Castle Street, Edinburgh EH2 3QA, UK

E-mail: luke@uservision.co.uk

\begin{abstract}
This study explores the premise that a high degree of realism is not a necessary condition for a 'sense of place' in mediated experiences. We report on the usefulness of an intentionally low fidelity virtual environment which relies on the metaphor of the 'tourist gaze' and the power of imagination to create a sense of place. This application was a non-immersive representation of Edinburgh. In evaluation, participants reported experiencing a sense of place rather than a mere collection of images. We discuss the results in the light of weak and strong cognitive representation and indicate potential applications.
\end{abstract}

Keywords: virtual reality; virtual environments; sense of place; sense of presence; tourist gaze; mediated experiences; cognitive representations.

Reference to this paper should be made as follows: Turner, P., Turner, S. and Burrows, L. (2013) 'Creating a sense of place with a deliberately constrained virtual environment', Int. J. Cognitive Performance Support, Vol. 1, No. 1, pp.54-68.

Biographical notes: Phil Turner is a Reader in the School of Computing at Edinburgh Napier University. His current research interests include the ontological foundations of user experience.

Susan Turner is a Senior Lecturer in the School of Computing at Edinburgh Napier University. Her current research interests include presence and qualitative methods in user experience.

Luke Burrows is a Usability Consultant at User Vision, Edinburgh. His work includes usability evaluation, user research and webpage optimisation. The application discussed in this paper was produced for his MSc Dissertation at Edinburgh Napier University. 
USAB 2010: HCI in Work \& Learning, Life \& Leisure, Klagenfurt University, 16.-17. September 2010.

\section{Introduction}

Excepting the visualisation of complex data, virtual environments usually include a representation of a real, imagined or stylised place. For example, sufferers of arachnophobia encounter virtual spiders in family 'kitchens' (e.g., Garcia-Palacios et al., 2002) and those traumatised by the $9 / 11$ bombings find themselves back at the World Trade Centre in New York (e.g., Difede and Hoffman, 2002) or in the jungles of Vietnam (e.g., Rothbaum et al., 2001). Training simulations are located in burning buildings; on board ship (Turner and Turner, 2002); in hospitals (e.g., Seymour et al., 2002) and on an aircraft or spaceship (e.g., Loftin and Kenney, 1995). Current video games offering desktop virtual reality are also situated in real or imagined places, ranging from 'real' battle scenes from the Second World War to those entirely conjured from the imagination. While such applications contextualise the experiences they provide by situating them in recreated places, the places themselves are intrinsic to historical, geographical, archaeological or 'armchair tourism' applications.

These virtual environments require specialist hardware to manage the $3 \mathrm{D}$ models, the tracking of the user's movements and direction of gaze (and often much more) all of which is needed to convey a sense of a place. And to fully realise a place, the full spectrum of sensory inputs (i.e., not just the visual appearance but the sounds, smells, tactile and kinaesthetic sensations of the place) need to be created and substituted as near-realistically as possible. Even then the virtual environments thus created are not as convincing as the real thing (see Turner and Turner (2006) for a discussion of this). To be clear, this approach locates the burden for veridicality on the virtual reality technology leaving the user of the system a relatively passive spectator: a 'tourist' as it was.

But, there is an alternative, the argument for which we will present in two parts and support by an empirical study. The first part of which is predicated on the word, 'tourist'. A tourist is one who visits a place for a short duration; a tourist is often guided to this or that sight; a tourist only experiences a place from the perspective or point-of-view of his or her body and through his or her eyes. This raises the question - why build a complete $3 \mathrm{D}$ recreation (complete with sensory substitution) when we only need to provide what the user/tourist actually experiences?

The second part of our proposal lies with what has been described as the book problem'. This term, originally coined by Frank Biocca, can be summarised as 'how is at that a medium as impoverished as static text can transport the reader to any and all situations and settings?' (Biocca, 2002). Since this is true of books, can it also be true of restricted virtual environments? The answer would seem to be yes, as there is abundant anecdotal evidence in support of this proposal. For instance, the early work of the Disney ${ }^{\mathrm{TM}}$ Corporation created a vibrant, talking mouse capable of adventures, of emoting and of being 'married' from a few well-crafted lines of black ink. The same is true of caricature where a politician can be captured by an exaggerated nose or snarling lips. There is also considerable evidence that we actually recognise simple, minimal drawings of people more quickly than other representations of them (e.g., Waltz, 1975). 
Thus, we propose a lightweight approach to the re-creation of places by bringing together the experience of the tourist and minimal, but evocative, representations. Thus, our aim is to illustrate the power of constrained virtual reality used to create what a tourist might experience of a real place.

We begin by reviewing what is experienced when we visit a place - the 'sense of place'. We then consider examples of the existing approaches to creating a sense of place in VR before considering the conceptual bases for our lightweight approach. An illustrative study of the constrained use of VR to re-create a place is then presented. We conclude with a discussion of potential cognitive mechanisms underlying the apparent power of a restricted VR experience and indicate further work and possible applications.

\section{Creating a sense of place in virtual reality}

As we have already noted, applications that aim to create places through the medium of virtual environments are encountered in wide range of arenas. Some recent instances from what is now a very long catalogue of published reports follow. In some contexts, including collaborative learning (e.g., Dickey, 2005) and some training applications (e.g., the emergency management simulation described in Li et al. (2005)) and games (Levy et al., 2009), the experience of a shared place is a background to the main tasks or activities. In others, the place itself is central to the purpose of the application. In the latter group, we find, among others, environments for the negotiation of land management policy (Bishop, 2008), virtual heritage and virtual museums (e.g., Champion, 2008; Sylaiou et al., 2010), training environments where the location is fore-grounded (for example, the military applications reported by Deaton et al. (2005)) and an important and growing collection of applications for psychotherapy and the amelioration of phobias. Typical among these are the treatment of low mood (Freeman et al., 2004), acrophobia (e.g., Emmelkamp et al., 2002), fear of flying (e.g., Krijn et al., 2007) and therapeutic environments for military personnel suffering from post-traumatic stress disorder (Ready et al., 2010; Yeh et al., 2009).

\subsection{Sensory substitution}

In the majority of these environments, reality is emulated as closely as can be managed and sensory inputs approach the full spectrum, as can be seen in the following two instances of therapeutic applications. In the virtual Iraq discussed by Yeh et al. (2009) which is delivered primarily through a Head-Mounted Display (HMD), the patient has access not only to exterior street scenes, but also to interiors and roof-tops, the environment is populated by animated civilian and military vehicles and pedestrians and is ".. adjustable for time of day or night, weather conditions, illumination, night vision ... and ambient sound (wind, motors, city noise, prayer call, etc.)". Not only that, but also olfactory stimuli can be delivered as appropriate by the clinician "as direct stimuli (e.g., scent of smoke as a user walks by a burning vehicle) or as cues to help immerse users in the world (e.g., ethnic food cooking). The scents selected for this application include burning rubber, cordite, garbage, body odour, smoke, diesel fuel, Iraqi food spices and gunpowder." Vibratory cues to accompany events such as explosions may also be present, while the experience is completed by a replica weapon for the patient, albeit without firing option. The rather less dramatic treatment for fear of flying discussed by Krijn et al. (2007) nonetheless includes limited movement within the 
constraints of the HMD and an aircraft chair, which vibrates with turbulence and at takeoff and landing.

In short, the design of such applications very often rests on the assumption that additional sensory inputs and ever-greater realism afford a corresponding improvement in user experience. In turn, this means that the design, implementation and delivery of such experiences, even now, impose heavy costs in terms of both time and technologies. Moreover, their very richness and near-fidelity bring their own problems, as expectations become raised to an ever-higher level. The experience of the BENOGO environment (Arnspang et al., 2002) illustrates some of these issues. The project was part of the EUfunded Presence I initiative and sought to develop and apply (then) innovative real-time image-based rendering technology to the task of recreating specific places. These $360^{\circ}$ photo-realistic visual representations were complemented by an appropriate sound field and augmented computer-generated objects and experienced through HMD and CAVE technologies. It was envisaged that BENOGO would permit its users to 'be' in places of personal, scientific or touristic interest without the need to 'go' there (hence the project title). While the technical developments in the project made considerable achievements, the experience of the places presented remained partial, as we elaborate in Turner and Turner (2006). In the environment of a highly realistically rendered botanical garden, for example, the very natural appearance of the leaves prompted the thwarted desire to reach out and touch them, while the convincing impression of depth elicited a similarly frustrated intent to move further into the scene. In a later experiment set in the foyer and stairs of an academic institution, participants were impressed by elegance and realism of their surroundings, but the chief contributor to the sense of 'being there' was a narrative plot, which involved their playing the role of a security guard. Other evidence indicates that fully featured and immersive virtual reality may not always produce more effective training, as the review in Bowman and McMahan (2007) suggests. Moreover, full replication of the real world and simulation of what are now estimated to be at least $20^{1}$ different senses are impossible both in principle and in practice.

\subsection{Spaces are different from places}

We emphasise 'place' in the same vein as the much-cited distinction made by Harrison and Dourish (1996), who position lived 'place' rather than geometric 'space' as the framework for design for computer-supported cooperative work and cognate domains. "Space is the opportunity; place is the understood reality." (Harrison and Dourish, 1996, p.67). Although Dourish (2006) later acknowledges that space itself may also be a product of social and cultural practice, the separation remains a cogent and useful one. As Casey (1997) observes, the earliest writers were clear about the fundamental link between being and place. In the 4th century B.C., for example, we find Archytas of Tarentum asserting that: "to be (at all) is to be in (some) place" (Casey, 1997, p.4). A little later, Aristotle conceives place as a container or boundary for an object, a concept perhaps echoed in the 21st century confines of the VR CAVE. However, from Plato onwards until recently, the archaic primacy and specificity of place is occluded by discussions of Euclidean space, in explications of the relationship between space and time, and in the hegemony of a positivist scientific paradigm directed at uncovering universally applicable laws. It is not until the late 18th century that the concept is reclaimed, notably in the writings of Kant, Whitehead, Husserl, Merleau-Ponty and Heidegger, who were all instrumental in re-introducing place to philosophical discourse. 
Most fundamentally of these authors, Heidegger identifies the existential character of being with inhabiting and dwelling. As Heidegger (1971) has noted, the use of language and philology affords insights into the nature of dwelling that he asserts is central to the having a sense of place or being-there. "The Old English and High German word for building, buan, means to dwell. This signifies: to remain, to stay in a place. The real meaning of the verb bauen, namely, to dwell, has been lost to us. But a covert trace of it has been preserved in the German word Nachbar, neighbour. The neighbour is in Old English the neahgehur; neah, near and gebur, dweller." Heidegger holds that human beings and the world are not distinct but one single entity resulting from Dasein's involvement in the world.

The thinking of the phenomenological geographer Edward Relph shares much common ground with these concepts (Relph, 1976, 2007). For Relph (1976), place is fundamentally lived, place identity comprising "the static physical setting, the activities and the meanings". Furthermore, places may be experienced from a perspective of 'insideness' or 'outsideness', concepts that broadly reflect the nature of one's involvement. Two sub-classes of insideness, as further explicated in the commentary by Seamon (n.d.), are of particular utility in the context of recreating the experience of particular places: behavioural insideness, which entails attention to the entities, appearance and activities of a place and vicarious insideness, a deeply felt but second-hand experience.

Sense of place is, necessarily, intimately related to the sense of presence. Presence as a phenomenon has been widely investigated over the last two decades in the context of virtual reality, other technologically mediated environments such as games, and more latterly, everyday situations such as telephone conversations. Numerous definitions of presence continue to be proposed and debated, but among the most cited are the perceptual illusion of non-mediation (Lombard and Ditton, 1997) and the sense of being there (Steuer, 1992 among others). We argue that place is a content factor contributing to presence: it is the there in the sense of being there. This is reflected by place-related items in a number of the most widely employed questionnaire instruments used to evaluate the sense of presence, as exemplified by Slater et al. (1994), and Kim and Biocca (1997).

\section{A lightweight approach to creating virtual places}

So, how might a lightweight treatment of virtual places work? As we have said, there are two starting points for such a project: first, the observation that people encounter mediated places, as visitors, or tourists; second, evidence for the potential effectiveness of limited or restricted presentation of recreated places. We begin with a discussion of the first of these.

\subsection{The tourist gaze}

Places in virtual environments are visited rather than inhabited. Considering a user of a virtual environment as a tourist suggests a different approach to designing applications that evoke real places. Here, our approach is informed by Urry's notion of the 'tourist gaze', an echo of Foucault's 'medical gaze' (Urry, 1990). A tourist searches for an experience of the other, for a different perspective. Tourists are aware of their transient condition and willingly submit to guided gazing at new landscapes, cultures and people, 
directed by anticipation and imagination. Tourist gazes may fall on static viewpoints or vistas from the window of car, train or boat, sign posted by roadside signs, tour guides, travel books, newspaper supplements, internet and mobile applications. Some places French towns are particularly good at this - prime the tourist gaze by announcing the attractions on the sign marking the town boundary "ses églises, son marché, ses fromages ..." As Culler (1981) notes, tourists act as semioticians, reading the landscape for signifiers of pre-established notions or signs derived from discourses of travel and tourism. In popular tourist locations, this guided perspective is engineered to meet the expectations of what the tourist wants to see, a manicured, and hyper-real cultural spectacle. Note, for example, Edinburgh's Royal Mile with its listed buildings, cobbles, tea shops and quaint bars, all combining to offer the quintessential 'Scottish' experience, but bearing little relation to normal everyday Scottish life. Essentially, this is the product of tourist willingness to be taken elsewhere, transported to another world, where they can gaze upon a mimesis of culture. Urry also notes that tourist relationships arise from a movement of people to, and their stay in, various destinations and there is a clear intention to return 'home' within a relatively short period of time.

Furthermore, as Tussyadiah and Fesenmaier (2009) observe, 21st century tourists are also armchair travellers experiencing the world via the virtual mobile gaze of film and video, so that

\begin{abstract}
"Viewers who have never been to New York appear to perceive the videos as a source of living their dreams and fantasies of visiting the city, while viewers who have experiences of visiting the city perceive the video as a media [sic] to bring back travel memories and re-experience the trip."
\end{abstract}

Pace Heidegger's views on dwelling and authenticity, many tourists emerge from their travels with a profound sense of having been in Scotland, Venice or Delft. The artefacts of the Royal Mile have been transformed into a deep and often memorable experience: in the vocabulary of Relph and Seamon, the conscientious tourist has become a behavioural and vicarious insider.

Next, we consider the effectiveness of limited or restricted presentation of places.

\title{
3.2 Proust and the madeleine
}

"... And as soon as I had recognised the taste of the piece of madeleine soaked in her decoction of lime-blossom, which my aunt used to give me [...] immediately the old grey house upon the street, where her room was, rose up like a stage set to attach itself to the little pavilion opening on to the garden, which had been built out behind it for my parents [...]; and with the house the town, from morning to night and in all weathers, the Square where I used to be sent before lunch, the streets along which I used to run errands, the country roads we took when it was fine. And as in the game wherein the Japanese amuse themselves by filling a porcelain bowl with water and steeping in it little pieces of paper, which until then are without character or form, but, the moment they become wet, stretch and twist and take on colour and distinctive shape, become flowers or houses or people, solid and recognisable, so in that moment all the flowers in our garden and in M. Swann's park, and the water-lilies on the Vivonne and the good folk of the village and their little dwellings and the parish church and the whole of Combray and its surroundings, taking shape and solidity, sprang into being, town and gardens alike, from my cup of tea." 
The above-mentioned quotation is from Remembrance of Things Past in which Proust (1913) famously described his narrator as being transported back to the places of his youth and becoming immersed in those memories by the taste of madeleine dipped in tea. Of course, this most celebrated of fictional accounts of being lost in the places of memory does not merely describe the narrator's experience, but takes us there alongside him to the lanes of Combray. The example demonstrates the power of the right stimulus to transport one to another place with something as simple as a fragment of cake or text on a page. Similarly, the watercolours of J.M.W. Turner convey a vivid sense of Venice through impressionistic sketches and stage designers convey an audience to the world of the drama through minimal props and scenery.

Of course, textual descriptions of places can transport us to anywhere that can be imagined. Yet how can this be given the relative paucity of such a stimulus? The answer lies with the power of our imaginations to create from what are necessarily incomplete descriptions - places. Biocca (2003) has suggested that in addition to physical and virtual spaces, we should recognise the role of 'mental imagery space', a theme that Baños and her colleagues (2005) have investigated empirically. Baños found that imagination has a limited, perhaps short-term, role in creating a sense of presence when compared with a virtual reality system. They conclude that the virtual environment helps people 'stay there', i.e., remain transported to the virtual space while the power of imagination alone tails off. In all, the 'book problem' remains just that - an unresolved problem ${ }^{2}-$ but irrespective of how we are able to experience a sense of presence or place from limited stimuli we can nonetheless take advantage of it, as we shall see in the next section.

Having reviewed the literature and having made our theoretical case for a lightweight approach to the re-creation of place, we now present empirical support for our argument.

\section{The Digital Visitor}

We have proposed that the nature of encounters with virtual places is that of tourism. Such a design metaphor, we suggest, would constrain expectations and thus reduce the jarring effects of any lack of veridicality. Just as importantly the limited interactions and low levels of fidelity presented would support transportation through the visitor's imagination, whether this be to known places such as Iraqi battlefields or to environments yet to be experienced in the real world.

We now describe the design, implementation and exploratory evaluation of a small-scale application that is intended to embody this approach using the simple means of a virtual Edinburgh conveyed through a selection of well-known photographed viewpoints. These are augmented by textual material about the area and appropriate city sounds: the hints, props and narratives to support the 'tourist' experience. The desktop application developed (Digital Visitor) allows its visitors to gaze in a guided fashion in the course of a visit to five well-known locations in and around the city of Edinburgh. A deliberate attempt has been made to present the application in an immediately recognisable narrative of the tourist-orientated site. We should stress that this explicitly touristic style is a metaphorical device to overcome the restricted nature of the medium. It does not imply that the intended primary users of this or other applications adopting the approach would be tourists themselves.

Each location is composed of a photographic image supplemented with descriptive text that tells the story of the location and contextualises it within the city, much as the text found on the information panels that abound at real-world viewpoints. This is 
intended to prime the visitor's imagination. The images are augmented by sound in the form of ambient recordings sourced from the position of image acquisition. The visitor is able to explore the location by changing their viewpoint, much as a tourist viewing a landmark might. This is achieved by initialising an interactive version of the location image so that parallax varies with the user's movements of the mouse pointer. To emphasise the staged nature of the experience, two further forms of visual effects are implemented. First, the images comprise multiple-layers creating a ' $2.5 \mathrm{D}$ ' effect and, second, the appearance of the sky was enhanced for each location. The substitute skies are bold and colourful effects that contribute to the overall drama and visual impact of the scenes. The aim was to allow visitors to suspend disbelief and explore the interactive virtual space as they might be a painting or cinematic film: such overtly artificial compositions counter the effect encountered in photo-realistic virtual reality applications that the very fidelity of the images paradoxically draws attention to any flaws and thus removes the observer from the scene. Figures 1-3 show representative screens from the application.

Figure 1 Home screen (see online version for colours)

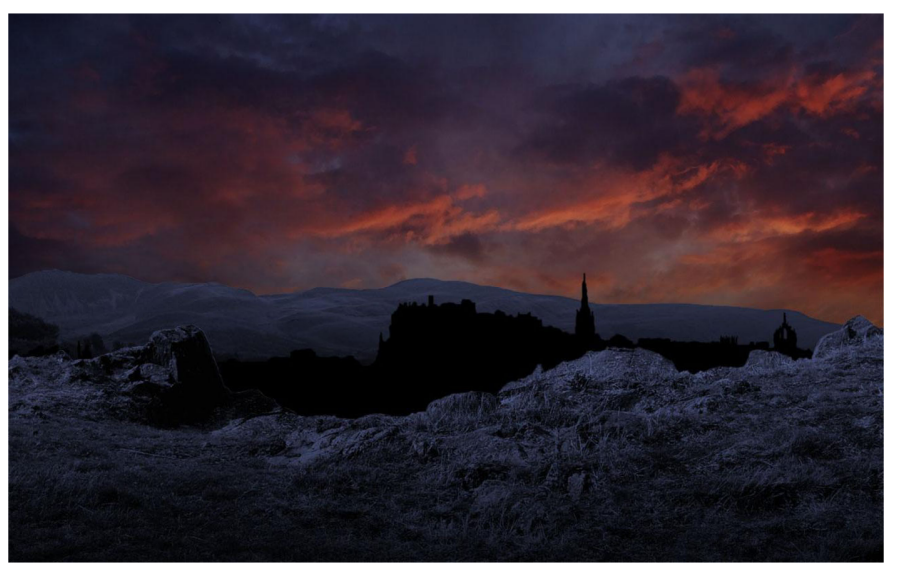

Figure 2 Calton Hill, Edinburgh showing 2.5D and enhanced sky effects (see online version for colours)

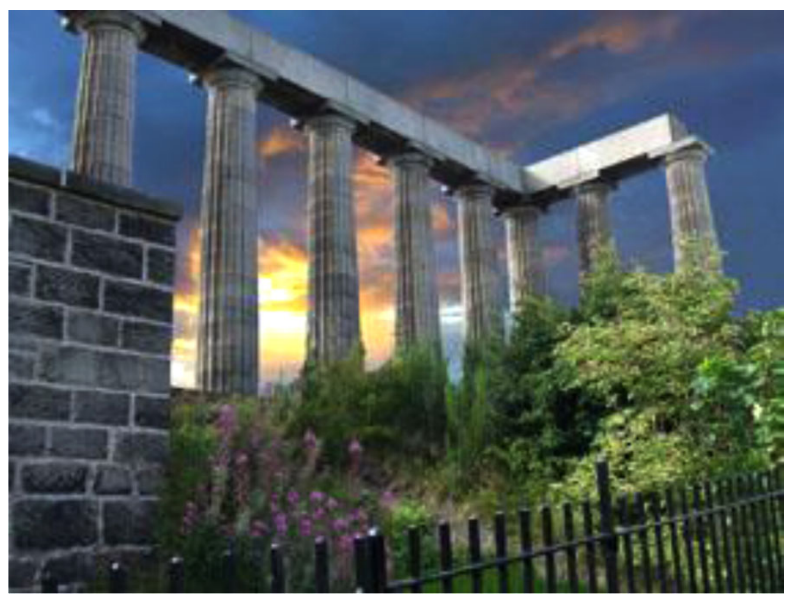


Figure 3 Text panel with navigation button (left) and viewpoint control (right) (see online version for colours)

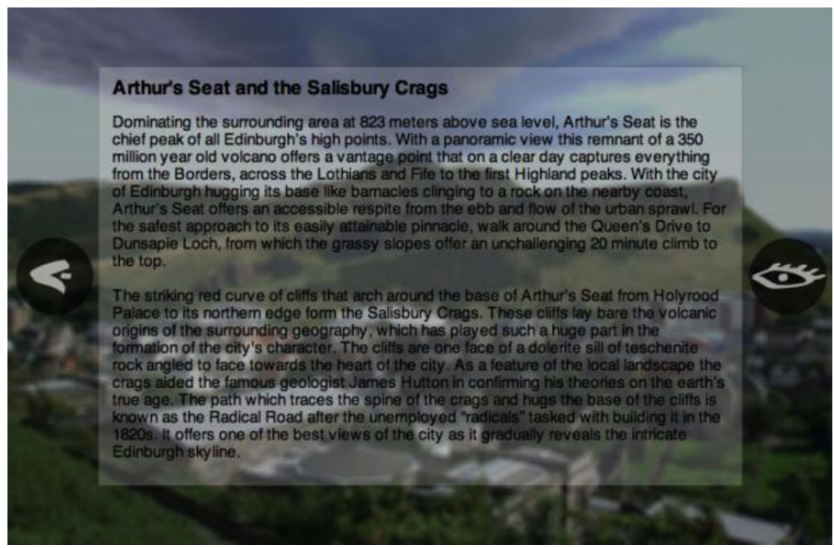

\subsection{The making of Digital Visitor}

Practical development of the application initially identified locations that would emphasise areas of interest and contain a high degree of visual impact, by walking around the city observing the ebb and flow of visitors and locals. Subsequent image acquisition avoided the capture of human beings, to avoid conflict between the static nature of the intended presentation in the application and the potential desire to interact with people depicted.

The final five locations were chosen for their visual impact and their immediately recognisable remediation in countless other images produced in media about Edinburgh (For the benefit of readers familiar with the city, they were North Bridge, Victoria Street, Edinburgh Castle, Calton Hill and Arthur's Seat.). The final sixth location forms the home screen, and was chosen for its classic overview of the city, capturing Edinburgh's characteristic skyline and enabling the positioning of the viewer in a detached yet recognisable location. To create a visually striking introduction, this image (please see Figure 2) was constructed from four photographs, each containing a different element of the landscape that embodies the city. This composite image provides both an overview of the city and the application, providing a fantastical vantage point from which the 'Digital Visitor' can sweep down as they travel to a location. The home screen is a night shot to distinguish it from the other locations visually, and additionally to lend it and the process of navigation and location selection an other-worldly tone. The selection of each main location image involved the consideration of lighting conditions and the weather. It was important to represent each location in similar lighting conditions (excluding the deliberately artificial additions of the background skies) to nurture the illusion of interconnectedness between locations and foster a sense of the city as a whole.

Images were imported into Adobe Photoshop where they were dissected by hand into four individual layers consisting of the foreground, front-middle ground, back-middle ground and background. This also required the meticulous work of digitally painting in any missing areas to cover the discrepancies and allow for the movement of each 
parallax layer. A series of striking images of skies were selected from the third author's photographic portfolio and inserted into the background layer. Once the layers for each location image had been rendered down into its individual layers, they were imported into Adobe Flash CS4 and inserted into a small individual movie. The parallax effect was achieved through the adaptation of the technique downloadable from www.Fuoridalcerchio.net, which provides an online resource for Flash developers. Sound was captured by setting each microphone up facing each other at 90 degrees with the centre directed towards the desired sound source. The small space between each microphone allows sound to reach them almost simultaneously and the capture of stereo sound. Sound was recorded in .wav format and later converted to an $\mathrm{mp} 3$ format to reduce file size. As the application neared completion, pilot trials with a single participant eliminated design flaws and to informed the length of subsequent evaluation sessions.

\subsection{Evaluation procedure}

Evaluation involved 25 participants drawn from a mixture of university and professional backgrounds. Their ages ranged from 19 to 45 , comprising 14 males and 11 females: all were computer-literate, familiar with the locations presented and had a good command of English. The intention was to emulate the typical use of a desktop application and to allow each user to engage with the application independently at their own pace. Their use of Digital Visitor and the reactions elicited were observed and noted by an experimenter. The session ended with a semi-structured interview. This was designed to elicit:

- Overall impressions of the experience of using the application

- What elements were odd or unusual

- What elements were of particular interest
- How the experience compared with Edinburgh itself

- What use the application could be suited for

- To what extent did users remember their experience as images that they saw or a place that they visited

In post-interview, the participants were asked to rate the aspects of the application on 10-point scales for the effectiveness of navigation, sound, text, interaction, locations, images, aesthetics and engagement.

\subsection{Results and discussion}

The results were broadly encouraging. This was despite several external uncontrolled disturbances to the sessions, which were conducted at one end of a laboratory otherwise populated by ordinary users, and the relatively poor sound quality provided by the desktop PC speakers. All participants easily navigated through the virtual city and readily engaged with the interactive viewpoints. Across all the rating scales, the poles being -5 (most negative) to +5 (most positive), the minimum mean rating was +2.9 and the 
maximum +4.4. The mean rating for each design feature and their standard deviations are shown here and in Figure 4:

\begin{tabular}{ll}
\hline Navigation: $+3.5(\mathrm{SD}=1.72)$ & Locations: $+4.4(\mathrm{SD}=0.75)$ \\
Sound: $+3.3(\mathrm{SD}=2.16)$ & Images: $+4.2(\mathrm{SD}=1.10)$ \\
Text: $+3.8(\mathrm{SD}=1.53)$ & Aesthetics: $+3.6(\mathrm{SD}=1.79)$ \\
Interaction: $+2.9(\mathrm{SD}=1.74)$ & Engagement: $+3.4(\mathrm{SD}=1.02)$ \\
\hline
\end{tabular}

Figure 4 Mean ratings for design elements (see online version for colours)

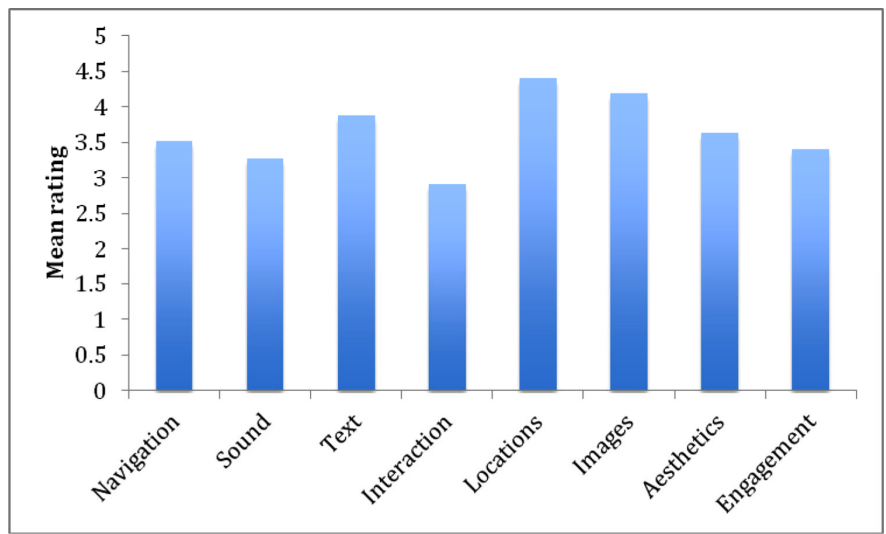

The response to the presentation of text was notably varied. Observation showed that a minority of individuals appeared not to read the text at all (although more than 11 out of the 25 participants awarded the maximum rating of +5 for its informativeness), and interview comments included the suggestion that it be moved to the margins of the screen.

As for the sense of place, in the semi-structured interviews participants spontaneously discussed their experience in terms of a physical location:

“... it felt like you were going on a journey through it, rather than it just bein' a sort of static, um ... even the way that Google Maps would be that kind of photograph, it felt like you were kind of moving through it rather than it just bein' pictures ..." - Participant N.

"Well the ... the background noise, it obviously made me feel like I was in sort of like, in the city ... drivin' in the city, nice!" - Participant C

Unusual ... the first like...you know the first page that was unusual, that was like coming to town from [laughs] ... no I just felt like I was coming to town from this place ... the home screen yeah." - Participant W

Although as in more heavyweight VR applications some design features were found to be frustrating:

“... like kind of 3D that you can move, but just a bit, I was hoping for, to more up and down as well ... I could move only a bit ... and not enough."Participant L

All participants alluded to the physical features depicted in the images, while other aspects generally agreed to be elements of a sense of place - personal meaning, the 
activities afforded and social interaction - were less frequent, being mentioned by only 8 , 6 and 2 of the 25 participants, respectively.

Of all the results, we were perhaps most interested by the responses to the question "When you think back about your experience, do you think of Digital Visitor more as images that you saw, or more as somewhere that you visited?" (Adapted from Usoh et al. (2000)). Participants rated their response on a scale from 1 (images) to 5 (somewhere visited). The mean rating was 3.6 , the mode and median both being 4 , indicating that a reasonable degree of place-like character has been evoked. This result compares well with reported responses to the same question in the evaluation of much more heavyweight immersive virtual environments, specifically an immersive virtual office (Usoh et al., 2000) and an immersive photorealistic representation of a staircase (Juan et al., 2006).

There are of course limitations to the inferences that may be drawn from these data. Full confidence in the relative power of restricted virtual environments would require comparative trials of applications such as Digital Visitor against directly equivalent, heavyweight versions. Furthermore, in the trial reported here, participants knew the city well - it remains to be seen how evocative the application would be for those who have slight or no familiarity with the real Edinburgh.

\section{Conclusion}

This paper has proposed a lightweight approach to the re-creation of places. The aim is to recreate the experience of place rather than to build a veridical model of a three-dimensional space. The nature of the cognitive representation of place needs a little thought. Clark (1997a, 1997b) has made considerable efforts to unpick and clarify the nature of representation, which he defines as 'information-bearing internal states'. He distinguishes between 'weak' and 'strong' representations (Clark and Grush, 1999). Strong representation is what most people would regard as genuine representation and the substance of cognitive processes. Strong representations are de-coupled from the immediate world and thus stand for things when they are removed from us (or us from them, in the case of distant places). Here, we see representation as re-presentation (to present again). In contrast, a weak representation is an internal state that is only capable of bearing information about an external object (event or person) when that object is available, proximal and ready-to-hand. Weak representations are found in what Clark describes as information and control systems rather than information-bearing states per se and as such facilitate our responsiveness to the environment (e.g., fight or flight). It is the differences between weak and strong representations that hold the key to understanding how restricted VR works.

Following Clark, we argue that the experience of a place experienced in a partial and constrained fashion as a tourist necessarily relies on a (strong) representation we create based on the impoverished data we have (just like we do when reading a description). Such representations are 'strong' precisely because they depend on information that is incomplete or removed from us. The burden of (cognitive) work lies with us - c.f. Baños et al.'s (2005) work in comparing imagination vs. virtual environments discussed earlier.

In contrast, when confronted with in a fully realised virtual environment, we are only required to create a weak representation of it and, for Clark, weak representations do not count as genuine representations. It is not that they do not stand for anything but they 
only become active when the individual is engaged with the world. They provide us with rapid feedback about proximal objects (e.g., an approaching lion) enabling us to respond to them effectively (e.g., running away). Clark has highlighted the evidence that it is the striate motor cortex that is responsible for encoding information related to proximal objects.

We do not suggest that the minimal approach to the creation of virtual places described in this paper could replace mainstream, heavyweight VR applications in all contexts. However, we argue that adopting the perspective of the user - the tourist gaze on the virtual place - and exploiting the power of imagination, or our familiarity with the world, or our ability to 'fill in the gaps' to create strong cognitive representations has clear potential as an alternative to modelling every last detail of the space. Such a strategy, for example, adds to the range of options available to VR designers of training applications, where the trainee's view of the surrounding world is constrained by a focus on the tasks in hand - medical examples spring to mind. Perhaps, the operating room could be (minimally) suggested while the focus of resources is placed on a veridical recreation of some part of a patient's body. More generally, this approach may be valuable in contexts where design and implementation resources are constrained.

\section{Acknowledgements}

We thank the participants in this study for their time and the reviewers of the earlier version of this paper for their helpful comments.

\section{References}

Arnspang, J., Benyon, D., Fahle, M.W., Granum, E., Madsen, C.B., Pajdla, T., Peleg, S., Smyth, M., Turner, P., Turner, S. and Weinshall, D. (2002) 'An investigation into virtual representations of real places', Proc. Fifth Annual International Workshop Presence 2002, Porto, Portugal, pp.66-78.

Baños, R.M., Botella, C., Guerrero, B., Liaño, V., Alcañiz, M. and Rey, B. (2005) 'The third pole of the sense of presence: comparing virtual and imagery spaces', PsychNology, Vol. 3, No. 1, pp.90-100.

Biocca, F. (2002) Presence Working Group Research Targets, Invited talk at the 'EU' of the European Commission, 10 January, Brussels.

Biocca, F. (2003) 'Can we resolve the book, the physical reality, and the dream state problems? From the two-pole to a three-pole model of shifts in presence?', Presentation at the "EU Future and Emerging Technologies, Presence Initiative Meeting", 5-7 May, Venice.

Bishop, I.D. (2008) 'Understanding place and agreeing purpose: the role of virtual worlds', Landscape Analysis and Visualisation, Lecture Notes in Geoinformation and Cartography, Part 5, pp.457-467.

Bowman, D.A. and McMahan, R.P. (2007) 'Virtual reality: How much immersion is enough?', IEEE Computer, Vol. 40, No. 7, pp.36-43.

Casey, E.S. (1997) The Fate of Place, University of California Press, Berkeley, Los Angeles, London.

Champion, E. (2008) 'Otherness of place: game-based interaction and learning in virtual heritage projects', International Journal of Heritage Studies, Vol. 14, No. 3, pp.210-228.

Clark, A. (1997a) 'The dynamical challenge', Cognitive Science, Vol. 21, No. 4, pp.461-481.

Clark, A. (1997b) Being There: Putting Brain, Body, and World Together Again. Cambridge, CUP. 
Clark, A. and Grush, R. (1999) 'Towards a cognitive robotics', Adaptive Behavior, Vol. 7, No. 1, pp.5-16.

Culler, J. (1981) 'Semiotics of tourism, American Journal of Semiotics, Vol. 1, Nos. 1-2, pp.127-140.

Deaton, J.E., Barba, C., Santarelli, T., Rosenzweig, L., Souders, V., McCollum, C., Seip, J., Knerr, B.W. and Singer, M.J. (2005) 'Virtual environment cultural training for operational readiness (VECTOR)', Virtual Reality, Vol. 8, No. 3, pp.156-167.

Dickey, M.D. (2005) 'Three-dimensional virtual worlds and distance learning: two case studies of active worlds as a medium for distance education', British Journal of Educational Technology, Vol. 36, No. 3, pp.439-451.

Difede, J. and Hoffman, H.G. (2002) 'Virtual reality exposure therapy for world trade center post-traumatic stress disorder: a case report', Cyber Psychology \& Behaviour, Vol. 5, No. 6, pp.529-535.

Dourish (2006) 'Re-space-ing place: 'place' and 'space' ten years on', Proceedings of CSCW '06, ACM Press, New York, pp.299-308.

Emmelkamp, P.M.G., Krijn, M., Hulsbosch, A.M., de Vries, S., Schuemie, M.J. and van der Mast, C.A.P.G. (2002) 'Virtual reality treatment versus exposure in vivo: a comparative evaluation in acrophobia', Behaviour Research \& Therapy, Vol. 40, No. 5, pp.509-516.

Freeman, J., Lessiter, J., Keogh, E., Bond, F.W. and Chapman, K. (2004) 'Relaxation Island: virtual, and really relaxing', Proceedings 7th Annual International Workshop on Presence, Valencia, Spain.

Garcia-Palacios, A., Hoffman, H.G., Carlin, A., Furness, T.A. and Botella, C. (2002) 'Virtual reality in the treatment of spider phobia: a controlled study', Behaviour Research and Therapy, Vol. 40, pp.983-993.

Harrison, S. and Dourish, P. (1996) 'Re-place-ing space: the roles of space and place in collaborative systems', Proceedings of CSCW 96, ACM Press, New York, pp.67-76.

Heidegger, M. (1971) Building Dwelling Thinking, Basic Writings, Routledge, London.

Juan, M.C., Banos, R., Botella, C., Perez, D., Alcaniz, M. and Monserrat, C. (2006) 'An augmented reality system for the treatment of acrophobia: the sense of presence using immersive photography', Presence, Teleoperators, and Virtual Environments, Vol. 15, No. 4, pp.393-402.

Kim, T. and Biocca, F. (1997) 'Telepresence via television: two dimensions of telepresence may have different connections to memory and persuasion', Journal of Computer Mediated Communication, Vol. 3, No. 2, Available from www.ascusc.org/jcmc

Krijn, M., Emmelkamp, P.M.G., Ólafsson, R.P., Bouwman, M., van Gerwen, L.J., Spinhoven, P., Schuemie, M.J. and van der Mast, C.A.P.G. (2007) 'Fear of flying treatment methods: virtual reality exposure vs. cognitive behavioural therapy', Aviation, Space, and Environmental Medicine, Vol. 78, No. 2, pp.121-128.

Levy, R.M., O'Brien, M.G., Aorich, A. (2009) 'Predicting the behaviour of game players - space syntax and urban planning theory as a predictive tool', Proc. 15th International Conference on Game Design, Virtual Systems and Multimedia, 2009 (VSMM ‘09), pp.203-208.

Li, L., Zhang, M., Xu, F. and Liu, S. (2005) 'ERT-VR: an immersive virtual reality system for emergency rescue training', Virtual Reality, Vol. 8, No. 3, pp.194-197.

Loftin, B.R. and Kenney, P.J. (1995) 'Training the hubble space telescope flight team', IEEE Computer Graphics, Vol. 15, No. 5, pp.31-37.

Lombard, M. and Ditton, T. (1997) 'At the heart of it all: the concept of presence', Journal of Computer Mediated Communication, Vol. 3, No. 2, www.ascusc.org/jcmc

Proust, M. (1913/1992) In Search of Lost Time. Volume 1: Swann's Way translated by Scott-Moncrieff, C.K. Terence Kilmartin and Andreas Mayor Revised by Enright, D.J., Chatto and Windus, London. 
Ready, D.J., Gerardi, R.J., Backscheider, A.G., Mascaro, N. and Rothbaum, B.O. (2010) 'Comparing virtual reality exposure therapy to present-centered therapy with 11 U.S. Vietnam veterans with PTSD', Cyberpsychology, Behaviour and Social Networking, Vol. 13, No. 1, pp.49-54.

Relph, E. (1976) Place and Placelessness, Pion Books, London.

Relph, E. (2007) 'Spirit of place and sense of place in virtual realities', Techné, Vol. 10, No. 3, pp.17-25.

Rothbaum, B.O., Hodges, L.F., Ready, D., Graap, K. and Alarcon, R.D. (2001) 'Virtual reality exposure therapy for Vietnam veterans with posttraumatic stress disorder', Journal of Clinical Psychiatry, Vol. 62, No. 8, pp.617-622.

Seamon, D (n.d) http://www.arch.ksu.edu/seamon/Relph.htm [last retrieved 22nd October 2010]

Seymour, N.E., Gallagher, A.G., Roman, S.A., O’Brien, M.K., Bansal, V.K., Andersen, D.K. and Satava, R.M. (2002) 'Virtual reality training improves operating room performance', Annals Surgery, Vol. 236, No. 4, pp.458-464.

Slater, M., Usoh, M. and Steed, A. (1994) 'Depth of presence in virtual environments', Presence, Teleoperators and Virtual Environments, Vol. 3, pp.130-144.

Steuer, J. (1992) 'Defining virtual reality: dimensions determining telepresence', Journal of Communication, Vol. 42, No. 4, pp.73-93.

Sylaiou, S., Mania, K., Karoulis, A. and White, A. (2010) 'Exploring the relationship between presence and enjoyment in a virtual museum', International Journal of Human-Computer Studies, Vol. 68, No. 5, pp.243-253.

Turner, P. and Turner, S. (2002) 'Contextual grounding in CVE design', Presence: Teleoperators and Virtual Environments, Vol. 11, No. 6, pp.665-676.

Turner, P. and Turner, S. (2006) 'Place, sense of place, and presence', Presence, Teleoperators, and Virtual Environments, Vol. 15, No. 2, pp.204-217.

Tussyadiah, I.P. and Fesenmaier, D.R. (2009) Mediating Tourist Experiences: Access to Places via Shared Video, Annals of Tourism Research 36, 24-40

Urry, J. (1990) The Tourist Gaze, Sage, London.

Usoh, M., Catena, E., Arman, S. and Slater, M. (2000) 'Using presence questionnaires in reality', Presence, Teleoperators, and Virtual Environments, Vol. 9, No. 5, pp.497-503.

Waltz, D (1975) 'Understanding line drawings of scenes with shadows', in Winston, P.H. (Ed.): The Psychology of Computer Vision, McGraw-Hill, New York, pp.9-91.

Yeh, S-C., Newman, B., Liewer, M., Pair, J., Treskunov, A., Reger, G., Rothbaum, B.O., Difede, J., Spitalnick, J., McLay, R., Parsons, T.D. and Rizzo, A.A. (2009) 'A virtual Iraq system for the treatment of combat-related post-traumatic stress disorder, Proceedings of IEEE Virtual Reality Conference 2009 (VR 2009), Lafayette, Louisiana, USA, IEEE, pp.163-170.

\section{Notes}

${ }^{1}$ This may appear surprising but our sense of time, temperature, orientation (whether we are upright or prone) and the many different forms of touch are now recognised to have expanded the traditional 5 senses.

${ }^{2} \mathrm{We}$ propose a potential mechanism in the concluding passages of this paper - see Section 5 . 